\title{
A Folha de Caxias e "a grande campanha em favor da infância desvalida" (1953-1956)
}

\author{
Amália Dias ${ }^{1}$ \\ Márcia Spadetti Tuão da Costa²
}

\section{Resumo}

Examinamos a atuação do jornal Folha de Caxias no processo de criação da Associação Beneficente de Menores e do Patronato São Bento, em Duque de Caxias (RJ). A Associação foi criada para instituir e dirigir o Patronato, destinado a educar crianças em situação de vulnerabilidade social. O jornal pautou o tema da "infância desvalida", defendendo que os menores "abandonados" nas ruas contribuíam para uma visão negativa da cidade. Na perspectiva teórico-metodológica adotada, a imprensa foi tratada como fonte e objeto de investigação. Palavras-chave: Imprensa; Infância desvalida; Patronato.

Folha de Caxias and "the great campaign in favor of underprivileged children" (1953-1956)

\section{Abstract}

The current study analyzes the performance of the newspaper Folha de Caxias in the development of Associação Beneficente de Menores (Beneficent Children's Association) and of Patronato São Bento (São Bento Boarding House), in Duque de Caxias County (RJ). The Association was launched to set and manage the Boarding House, which was designed to educate socially vulnerable children. The newspaper addressed the "underprivileged childhood" issue and argued that the "abandoned" minors on the streets contributed to the negative perception about the city. The press was addressed as source and object of investigation, according to the herein adopted theoreticalmethodological perspective.

Keywords: Press; Underprivileged childhood; Boarding house.

Le journal Folha de Caxias et «la grande campagne en faveur de l'enfance en détresse» (1953-1956)

\section{Résumé}

L'objectif de cette étude est d'examiner la performance du journal Folha de Caxias dans le processus de création de l'Association de Bienfaisance des Enfants et du Patronage São Bento à Duque de Caxias (RJ). L'Association a été créée pour établir et diriger le Patronage, qui a été conçu pour éduquer les enfants en situation de vulnérabilité sociale. Le journal a adopté le thème «l'enfance en détresse» en soutenant que les enfants "abandonnés» dans les rues contribuaient à une vision négative de la ville. Dans la perspective théorique et méthodologique adoptée dans cette étude, la presse a été analysée à la fois comme source et objet d'investigation.

Mots-clés: La presse, L'enfance en détresse, Le patronage.

\section{Introdução}

Os estudos sobre instituições escolares têm recebido atenção nos debates teóricometodológicos do campo da história da educação, principalmente, pela perspectiva de estimular

\footnotetext{
${ }^{1}$ Faculdade de Educação da Baixada Fluminense (UERJ/FEBF), Duque de Caxias, amaliadias@gmail.com.

2 Centro de Pesquisa, Memória e História da Educação da Cidade de Duque de Caxias e Baixada Fluminense (CEPEMHEd), Duque de Caxias, mardetti.tuao@gmail.com.
}

Periódico Horizontes - USF - Itatiba, SP - Brasil - e019046 
que os pesquisadores investiguem o processo de institucionalização, as trajetórias, as mudanças de configuração, as relações das instituições com a sociedade local na qual emergem. Nessa linha, a pesquisa sobre a instituição educativa Patronato São Bento, fruto de uma dissertação de Mestrado, considerou a "antessala" de sua fundação, o debate dos anos anteriores sobre a questão da infância desvalida na cidade, que repercutiu, posteriormente, na fundação do Patronato em 1959.Interessados no estudo do Patronato, buscamos nos jornais locais notícias sobre a instituição, posto que

O jornal como fonte histórica potencial é um lugar-espaço social onde ocorreram e ocorrem relações diversas alimentadas pela ação social de quem, direta e indiretamente, está presente na notícia e na produção do jornal apuração dos fatos, redação do texto e materialização gráfica (edição, ilustração e diagramação na página). Como tal, imprime o cotidiano de uma cidade, de um país, do globo (RIBEIRO; SILVA; SILVA, 2014, p.228).

Nas páginas do jornal $A$ Folha de Caxias $^{3}$ encontramos denúncias constantes sobre a ocorrência de crianças mendicantes nas calçadas, a participação de menores em roubos e delitos, a exploração sexual de menores em hotéis da cidade, principalmente no distrito-sede, ou seja, na área mais urbanizada do município de Duque de Caxias, situado em região metropolitana da cidade do Rio de Janeiro ${ }^{4}$.

Iniciamos a análise sobre as edições de 1953 - ano de fundação do jornal e do começo da campanha - e encerramos em 1956. Esse recorte temporal se justificou pelo fato de 1955 e 1956 terem sido os anos de instituição da Associação Beneficente de Menores ( $A B M)$, período de maior intensificação de notícias relacionadas à mesma. A criação da ABM, destinada a fundar o Patronato, será significada pelo jornal como resultado de uma campanha promovida pelo

\footnotetext{
${ }^{3} \mathrm{O}$ jornal teve seu primeiro número publicado em 22 de agosto de 1953, com o nome $A$ Folha de Caxias. Segundo o acervo que consta no Instituto Histórico Vereador Thomé Siqueira Barreto, a partir da edição de 10 de maio de1955, o jornal passou a ser nomeado Folha de Caxias. De 1 e 2 de julho de 1956 em diante, consta como Folha da Cidade. Manteremos nesse artigo o primeiro nome, $A$ Folha de Caxias, mas nas referências completas das matérias citadas, indicaremos o nome do jornal correspondente ao ano da matéria.

${ }^{4}$ Duque de Caxias havia se emancipado de Nova Iguaçu em 1943, e sofria, desde a década de 1930, um acelerado processo de ocupação urbana, devido ao impacto de diferentes políticas ruralistas implementadas no período varguista, como, por exemplo, as políticas de saneamento do território para revalorização fundiária e recuperação agrária, criação de núcleos coloniais agrícolas e fundação da Fábrica Nacional de Motores (SOUZA, 2014, p.90). Ligada ao Distrito Federal pela malha ferroviária e pelas estradas de rodagem, a região se desenvolveu em estreita conexão com a capital federal, principalmente pela oferta de mão-de-obra. Sobre a história do município de Duque de Caxias, ver também Braz e Almeida (2010).
}

Periódico Horizontes - USF - Itatiba, SP - Brasil - e019046 
mesmo em prol da "infância desvalida" de Duque de Caxias. Nesse sentido, como referencial teórico, lidamos com a fonte jornalística atentos à necessária problematização de "seu conteúdo e sua forma, seja escrita ou iconográfica; assim como a visão de mundo de quem o produz e quem o consome. Fazer isso supõe ir além do empiricamente observável, mediante uma intenção inquiridora" (RIBEIRO; SILVA; SILVA, 2014, p.229). Entendemos como referencial teórico que a imprensa, enquanto produto social, é uma estratégia educativa (FARIA FILHO, 2002, p.134), recurso polifônico de operação de hegemonia. Na construção da hegemonia, a imprensa é um recurso de defesa de propostas e visões de mundo, e sua ação busca disseminá-las (BUTTIGIEG, 2003, p.47).

Por isso, apresentamos na primeira seção do artigo a análise das manchetes e matérias que permitem conhecer a construção do discurso sobre os menores como um "problema" para a sociedade caxiense, onde identificamos um conjunto de discursos e práticas de judicialização da infância pobre, associada à criminalidade. Assim, as autoridades policiais e judiciais são chamadas a assumir a responsabilidade com essa infância "transviada" em Duque de Caxias. Essa mesma característica é afirmada pela historiografia das políticas públicas de assistência social para a infância no Brasil na primeira metade do século XX (PASSETTI, 2000; RIZZINI, 2011). Os discursos e ações destinados a promover a "assistência social" estavam imbricados também, no cenário nacional, com os projetos de industrialização e com as migrações internas que incidiam sobre as políticas de ordenação dos espaços urbanos e do controle de suas populações.

Na segunda seção do artigo, desdobramos a cobertura do jornal sobre o resultado da campanha, que resultou na criação da ABM e do Patronato São Bento como "soluções" para o problema do "menor abandonado". Os patronatos agrícolas eram destinados a essa infância classificada como "desvalida". Segunda Sônia Mendonça, "[...] os patronatos destinavam-se a assistir a infância desvalida das cidades, atendendo aos interesses dos segmentos urbanos e industriais, empenhados em construir uma imagem de "cidade profilática" e moderna" (MENDONÇA, 2010, p.36). Esse tipo de instituição ainda agregava as "vantagens apregoadas na época como ideais para formação e regeneração de crianças", além da "superioridade da vida do campo sobre a cidade" (RIZZINI, 2011, p.259). Na última seção, por meio das associações entre iniciativa privada e confessional, governo municipal e políticas federais de assistência, retomamos a análise sobre a função social do jornal na promoção da campanha. Apresentamos 
a adesão de quadros da Igreja Católica local na campanha que se resultou na institucionalização do Patronato como a solução para a infância desvalida de Duque de Caxias, quando, tratava-se, mais de uma ação de "higienização" e remoção das camadas pobres e consideradas "delinquentes", das ruas principais da cidade.

\section{“Obra inadiável: amparar a infância desvalida"}

Ao buscarmos compreender as forças que compunham o jornal e quais interesses o mesmo defendia, cabe notar que o periódico foi um órgão oficial da Associação Comercial de Duque de Caxias, até 31 de janeiro de 1954. A partir de 7 de fevereiro de 1954, passou a constar como: "Órgão livre e independente"; e de 14 de março de 1954 em diante, a informação foi substituída por "Independência na conduta e Fidelidade nas informações". Teve como diretores Zoelzer Poubel Vidaurre, Ruyter Cleves Poubel Vidaurre e Mariano Sendra dos Santos, que eram quadros dirigentes da Associação Comercial.

A análise do jornal permite afirmar que havia a preocupação com a ordem social, ao mesmo tempo em se desejava demonstrar que a cidade de Duque de Caxias tinha "progresso" semelhante ao Rio de Janeiro, Distrito Federal. Havia uma tentativa de desacreditar a conotação violenta que era atribuída ao município de Duque de Caxias pela imprensa fluminense, tanto que o jornal publicava que a definição do município, nos diferentes jornais do Distrito Federal, era um "aposto incorreto e inoportuno que uma cidade laboriosa e proba recebe, o de 'terra sem lei'” (CAXIAS, ESSA INCOMPREENDIDA, 1953, p.3).

Para a apresentação dos resultados da pesquisa nesse artigo, optamos metodologicamente por elencar parte das manchetes que abordaram o tema do "menor", de modo a demonstrar a constância do tema na campanha do jornal. Cabe lembrar que "A manchete diz a ao leitor o que o jornal quer que ele leia primeiramente na página" (RIBEIRO; SILVA; SILVA, 2014, p.228). A diagramação das matérias jornalísticas possui uma "intencionalidade claramente educativa", pois coloca "em circulação uma série de matérias e assuntos que, em sua generalidade, não deixavam de compor uma representação sobre suas ideias de reforma das condutas e dos costumes" (FARIA FILHO, 2002, p.135). Nessa perspectiva, ressaltamos a importância da campanha promovida pela imprensa local de Duque de Caxias para 
transformar em pauta da cidade o enfrentamento do problema do "menor abandonado".

Desde as primeiras edições do jornal, em 1953, era pautado o tema dos delitos cometidos por "menores" nas principais ruas da cidade, o que prejudicava a imagem de progresso que se tentava imprimir na cidade, como podemos perceber nas manchetes que seguem: "Engraxates barulhentos" (ENGRAXATES..., 05/09/1953, p.4) "Menores abandonados roubam casas em Caxias" (MENORES..., 11/10/1953, p.6), “Com 17 anos já está na senda do crime: em outro local da presente edição uma notícia sobre vários assaltos praticados por menores em nossas casas comerciais" (COM..., 11/10/1953, p.2). Percebemos uma incidência de reportagens que tratavam desse aspecto e a isso atrelamos a questão econômica, a defesa do setor de comerciantes assumida pela A Folha de Caxias. Ainda em 1953, emerge a sugestão da necessidade de uma instituição que abrigasse o "menor" em conflito com a lei. Como podemos perceber no relato do jornal, o "menor" de 17 anos que havia sido preso inúmeras vezes, continuava incorrer no mesmo crime e havia a pergunta: “Que fazer?” (COM 17 ANOS JÁ ESTÁ NA SENDA DO CRIME..., 11/10/1953, p.2). Edson Passetti (2000) lembra que o termo "menor" foi historicamente destinado aos jovens e crianças "provenientes das periferias das grandes cidades, filhos de famílias desestruturadas, de pais desempregados, na maioria migrantes, e sem noções elementares da vida em sociedade" (p.357). São considerados menores não apenas pela idade jurídica, mas por serem "procedentes dos estrados mais baixos da hierarquia socioeconômica" (PASSETTI, 2000, p.357).

Outra reportagem, publicada algumas semanas depois, criticava o fato do "assaltante" (referindo-se ao "menor") ter sido posto em liberdade. Algumas perguntas retóricas indicavam as sugestões da imprensa: "Por que não foi enviado para uma casa especializada, onde recebendo trabalho e tratamento psicológico, pudesse regenerar-se e ser mesmo útil à coletividade?"; "Como se pode conceber que um jovem, em pleno verdor da idade, sendo um personagem perturbador da paz social, seja assim colocado novamente no caminho da degradação?" E a última pergunta cobrava uma atuação do Estado e apontava uma possível solução: "Será que o Estado do Rio, com tantas terras a perder por essas baixadas, não possuía um pequeno núcleo agrícola para os desajustados e delinquentes?" (POSTO EM LIBERDADE O ASSALTANTE..., 25/10/1953, p.4).

As relações entre infância pobre, abandonada, criminalidade e o fomento de políticas de

Periódico Horizontes - USF - Itatiba, SP - Brasil - e019046 
recolhimento desta infância em instituições específicas, como observamos em Duque de Caxias, também são verificadas em outros estudos de história da educação sobre o período republicano. As associações entre pobreza, vadiagem e delinquência, camadas pobres e camadas perigosas constituíam os diagnósticos sobre os problemas sociais e mobilizava a intervenção estatal por meio de políticas destinadas às camadas pobres, como o Código de Menores de 1927. O asilamento e a educação por meio do trabalho eram prescritos como antídotos para o enquadramento dos supostos desajustados (PASSETTI, 2000). Ao longo dos governos de Getúlio Vargas, uma gama de iniciativas buscou criar um aparato assistencialista para essa "infância desvalida", como política de Estado, por meio da criação de agências, legislação e ações filantrópicas lideradas pela esposa do Chefe de Estado (RIZZINI, 2011).

No ano de 1954, o jornal continuava a abordagem sobre a questão da violência. Entre as manchetes, destacamos: "Perigo, salve-se quem puder" (PERIGO - SALVE-SE QUEM PUDER,17/01/1954, p.1); "Na avenida Duque de Caxias escuridão e perigo" (NA AVENIDA DUQUE DE CAXIAS..., 31/01/1954, p.5); “Onda de assaltantes” (ONDA DE ASSALTANTES,06/05/1954, p.14) e "O vício assalta as ruas" (O VícIO ASSALTA AS RUAS, 18/07/1954, p.3). O jornal também apresentava, na última página, uma coluna com os assuntos policiais, mas as matérias acima citadas tinham mais destaque e ocupavam, por vezes, a primeira página. De todas as matérias em destaque anteriormente, a que obteve maior ênfase no jornal foi a que ocupou três páginas, inclusive a primeira página, que se referia à "onda de assaltantes". Era complementada com informações como "quatro bandos de facínoras armados até os dentes, semeiam a morte e o terror", "estabelecimentos assaltados em pleno dia no centro da cidade", "rapazes de 18 anos entre os bandidos" (ONDA DE ASSALTANTES,06/05/1954, p.1-4).

A relação entre infância e crime é tecida por uma presença constante de manchetes como: "Em Caxias: Crianças na senda do crime" (EM CAXIAS: CRIANÇAS NA SENDA DO CRIME, 21/02/1954, p.3); "Como falou o Juiz - A infância abandonada" (COMO FALOU O JUIZ, 25/04/1954, p.4); "Persiste a jogatina de menores nos parques de diversões" (PERSISTE A JOGATINA DE..., 16/05/1954, p.1), "Olhe as crianças meritíssimo Juiz" (OLHE AS CRIANÇAS..., 16/05/1954, p.1) e "Infância abandonada" (INFÂNCIA ABANDONADA, 29/08/1954, p.3). A reportagem "Crianças na senda do crime" tratava das crianças que frequentavam o campo de futebol e se juntavam aos adultos para jogarem "baralho, dados e outros tipos de jogos de azar", 
"enquanto os atletas" disputavam "as partidas de futebol". A matéria condenava o fato de que "... o mais abominável de tudo" era "ver as crianças de 7 a 13 anos misturadas com adultos inteiramente entregues ao vício" (EM CAXIAS: CRIANÇAS NA SENDA DO CRIME, 21/02/1954, p.3). Havia uma solicitação para que o Juiz Dr. Navega Cretton fizesse algo para que "êsses meninos sejam salvos" (OLHE AS CRIANÇAS... 16/05/1954, p.1). A cobrança se inscrevia juntamente com denúncias de negligência por parte das autoridades, como na matéria "Obra inadiável: amparar a infância desvalida":

Não cremos que as autoridades o ignorem. Os chamados 'Parques de Diversões', que outra coisa não são que antros de jogatina e perdição funcionando com a complacência da Polícia e da Prefeitura, são o ponto de distração de centenas de crianças, de 10 a 18 anos, que debruçam nas mesas de jogo até altas madrugadas. E nunca uma providência cabal foi tomada (OBRA INADIÁVEL..., 21/11/1954, p.1).

Ainda segundo a reportagem, essa situação dos menores exigia um juiz de menores que exercesse uma "fiscalização" sobre os mesmos, assim como preconizava a necessidade de criação de um "albergue subvencionado" em "terreno fora do centro urbano" (OBRA INADIÁVEL..., 21/11/1954, p.1). O jornal sugeria a colaboração entre o juiz, o prefeito e o delegado da cidade: "No caso da infância não cremos que haja interesses subalternos, portanto é uma causa que merece o apoio e a solidariedade dêsses três poderes municipais" (OBRA INADIÁVEL..., 21/11/1954, p.1). O jornal defendia que era "dever da Justiça principalmente e de qualquer cidade em particular, orientar os menores que não têm pais, evitando-os da perdição e da fome" (JUIZ DE MENORES,12/12/1954, p.1). Essa afirmação de que o poder público precisava assumir a responsabilidade pelos menores apoiava-se na legislação do período e repercutia uma narrativa de que os menores não tinham famílias, eram órfãos, "menores abandonados". Desde 1923, quando foi criado o primeiro Juízo de Menores no país, foi instituído um protagonismo da atuação do poder judicial que se perpetuaria na história da assistência pública no país (RIZZINI, 2011, p.242).

Uma das principais características dessas políticas de assistência exercida pelo Estado era a internação dos menores considerados em situação de abandono (PASSETTI, 2000; RIZZINI, 2011). Assim, em 1955, identificamos um aumento de matérias acerca da temática do "menor". 
Cada reportagem relacionada a esse tema apresentava o espaço de internamento local como a solução para o "problema", posto que "Caxias possue uma infância sem amparo. Existem dezenas de pequenos seres no mais negro abandono, na maioria desajustados de toda espécie. [...] Só uma escola profissional ou uma colônia agrícola solucionará o grave problema" (MENORES NO CINEMA, 01/05/1955, p.3).

A vinculação entre os menores e o cometimento de roubos e outros crimes na cidade era tratada no jornal paralelamente ao assunto do lenocínio, crime no qual as crianças eram as vítimas. Segundo o jornal, lenocínio era o lucro obtido com a prostituição, através do aluguel de quartos para esse fim. Os hotéis da cidade se prestavam a essa finalidade ou para "crime de sedução", o que conferiu aos hotéis, o título de "casas de prostituição" (PROSTITUIÇÃO..., 2930/07/1956, p.1)

Em 1954, o jornal fazia "um apelo" ao Secretário de Segurança Pública, em matéria cujo subtítulo era "o lenocínio e o jogo" (UM APELO AO SR SECRETÁRIO..., 17/01/1954, p.2). Esses eram assuntos associados ao menor e à violência, e era cobrada a atuação das autoridades, do juiz de direito, da polícia, dos vereadores e dos demais políticos na resolução desses "problemas". Dessa forma, o crime de lenocínio era vinculado a um atentado à moral e na reportagem em que tratava do "Insulto as famílias e a decadência moral", era apresentado pelo jornal o combate a esse crime como uma "campanha de recuperação moral da sociedade local" (INSULTO AS FAMÍLIAS..., 31/01/1954, p.1).

Na matéria intitulada "As autoridades e o lenocínio", o jornal afirmava: "O problema do meretrício nesta cidade, parece ser um problema sem solução aparente" (AS AUTORIDADES E O LENOCíNIO, 11/09/1955, p.1). Havia denúncias e insinuações de que os comerciantes locais lucravam com tal crime. Em algumas reportagens, era indicado que alguns dos próprios políticos, tanto vereadores como deputados, estavam envolvidos nessa ação criminosa. $\mathrm{O}$ tratamento que era dado à prostituição das meninas e a resistência que o juiz enfrentou no combate dessa atividade demonstram a naturalização da questão, principalmente, ao analisarmos o posicionamento dos hoteleiros e do próprio jornal, que posteriormente, passou a tratar do assunto como "mal necessário ou fatos da vida social" (PROSTITUIÇÃO..., 29-30/07/1956, p.1).

Cabe um destaque para o fato de que, embora o lenocínio tenha evidenciado o grande número de meninas pobres que eram vitimadas, o projeto do Patronato não as incluiu. Embora

$$
\text { Periódico Horizontes - USF - Itatiba, SP - Brasil - e019046 }
$$


a ABM tenha se ocupado de um trabalho com o menor, e a prostituição de meninas fosse algo inquietante no território, como notamos pelas notícias do jornal, a instituição atendeu as meninas apenas durante o ano de 1957. Se os delitos cometidos pelos menores que vagavam pelas ruas da cidade precisavam ser contidos, os crimes cometidos com a exploração das meninas, esses, poderiam ser suportados. Afinal, a campanha contra o lenocínio não teve a mesma adesão que a campanha sobre o asilamento dos meninos. No lenocínio, lucravam os donos de hotéis, comerciantes e políticos influentes na cidade, apesar do anúncio de que a justiça lutava contra a ideia de que a cidade era terra "do vício e do crime" (CAXIAS ERA A TERRA..., 26/27/08/1956, p.15).

\section{A "vitória da sociedade caxiense"}

Em 1955, a mobilização promovida pelo jornal alcançava os primeiros resultados. O jornal articulava um "nobre movimento de solidariedade humana" em que o Juiz de Direito, Ary Fontenelle e o Prefeito, Francisco Corrêa, apoiavam a iniciativa do diretor do jornal $A$ Folha de Caxias, que era realizar uma mesa redonda que abordaria o assunto "Amparo a infância abandonada de Caxias". Essa foi a convocatória, feita na primeira página do jornal, em maio de 1955 (AMPARO A INFÂNCIA..., 29/05/1955, p. 1). Em junho, a mesma manchete tornou aparecer e dizia:

Tudo leva a crer que será uma grande vitória para o Município a iniciativa desse jornal, de promover uma reunião entre as autoridades responsáveis de Caxias, a fim de debaterem o problema do menor abandonado, da máxima importância do ponto de vista social e humano.

FOLHA DE CAXIAS teve ocasião de comunicar a ideia ao prefeito Francisco Corrêa e ao juiz de Direito, Dr. Ari Pena Fontenele, recebendo desses ilustres cidadões a palavra de apoio incondicional ao nobre movimento, que visa a salvar da fome e do crime, dezenas de pequenos caxienses sem lar e sem amparo. Talvês em nosso próximo número possamos anunciar a data escolhida para a reunião das autoridades municipais e representantes da Câmara Municipal e do Comércio, bem como damas da sociedade caxiense dispostas a se unirem a esse movimento humanitário e patriótico (AMPARO A INFÂNCIA..., $12 / 06 / 1955$, p.4).

O jornal reconhecia seu protagonismo na mobilização das reuniões:

Periódico Horizontes - USF - Itatiba, SP - Brasil - e019046 
Nós, da 'FOLHA DE CAXIAS', como incentivadores desse movimento, tudo faremos em busca de uma solução, com o Govêrno ou sem o Govêrno, mas desde já lançando o nosso mais veemente apelo às autoridades para que adotem providências de caráter urgente e imediatas para que seja sanado sem demora esse cancro social antes do quê seja muito tarde (BALANÇO TRÁGICO DE CAXIAS, 12/06/1955, p.5).

No planejamento da primeira reunião previa-se ouvir a experiência do Sr. Jorge Veríssimo, que tinha administrado por mais de 30 anos o "Patronato de Menores Casemiro de Abreu" (PATRIOTISMO E ABNEGAÇÃO..., 29/11/1953, p.1). Pretendia-se avaliar a possibilidade de ser a ele entregue a "incumbência de assistir as crianças": "O Sr. Veríssimo comparecerá à reunião e dirá das possibilidades que tem em amparar a infância, isto é, ensino profissional, moral, intelectual, físico, etc. Depois exporá os recursos de que precisa e a proposta será submetida à discursão [sic.]" (AMPARO A INFÂNCIA..., 12/06/1955, p.4).

O jornal fazia o relato sobre a primeira reunião com a data, o horário, o local em que havia acontecido e o nome das autoridades presentes:

aparecendo o Prefeito Sr. Francisco Corrêa, o Juiz de Direito da Comarca, Dr. Ary Fontenelle, Deputado Sá Rêgo, o Presidente da Associação Comercial, Sr. José Maia, o Delegado de Polícia, Dr. Amil Nei Richaid, vereadores Eduardo Walsh e Francisco Estácio, representantes do Comércio e da Imprensa (BALANÇO TRÁGICO DE CAXIAS, 12/06/1955, p.5).

É importante observar os agentes que estavam envolvidos nesse processo, integrantes da sociedade política e civil local. Outras matérias na mesma edição continuaram a ser apresentadas com destaque, como o levantamento feito pela Delegacia de Polícia da cidade, que trazia o quantitativo das crianças que viviam nas ruas: "Balanço Trágico de Caxias: 800 crianças desamparadas". Esse balanço foi apresentado pelo Delegado de Polícia, Dr. Amil Nei Richard, na reunião convocada pela A Folha de Caxias, para tratar da temática do "menor desamparado". Embora o delegado alegasse que esse era um "problema" que todo o país sofria, o Dr. Amil Nei afirmava que "em nenhum lugar do mundo verificamos o grau de impunidade do problema como aqui [em] nossa infausta e abalada Duque de Caxias" (BALANÇO TRÁGICO DE CAXIAS, 12/06/1955, p.5). O delegado declarava que dos 800 "menores" relacionados, 600 não conheciam os pais. O delegado relatou que a cada noite, a polícia era obrigada a prender "cêrca de 30 a 40 menores abandonados sem residência e sem conhecimento" sobre quem poderiam 
ser "seus pais e parentes".

O juiz de direito, segundo relato do jornal, complementava a informação ao dizer que muitos desses "menores" não eram do local, sendo "foragidos da Capital": "Caxias, cidadefantasma, sempre presente nas manchetes dos jornais, e no noticiário criminal, é logo lembrada pelos desajustados, pelos fracassados, pelos que precisam refúgio, e agora, também pelos menores que fogem da Capital” (BALANÇO TRÁGICO DE CAXIAS, 12/06/1955, p.5). Um dos desdobramentos da primeira reunião foi que a solução do problema da infância desvalida seria a construção de Patronato Agrícola e Profissional:

Nos debates chegou-se a conclusão, aceita por todos de que sem a ajuda do Govêrno, nada seria possível fazer, ficando resolvido que o Delegado de Polícia, Dr. Amil Richaid, providenciasse no sentido de colher informações precisas à respeito da maneira mais prática e urgente de obter do Govêrno uma área de terras com prédios suficientes para facilitar o abrigo da totalidade dos menores abandonados.

Nova reunião está marcada para a próxima terça-feira, dia 14 do corrente quando será nomeada uma Comissão constituída dos mais expoentes da sociedade caxiense, a qual se incumbirá de movimentar recursos para a instalação nas terras concedidas pelo Govêrno, de um Patronato Agrícola e Profissional, onde serão ministrados aos menores ensinamentos de horticultura, apicultura, e outros, como também ensinos profissionais diversos (BALANÇO TRÁGICO DE CAXIAS, 12/06/1955, p.5).

A Folha de Caxias organizou e noticiou as reuniões que se sucederam para tratar o tema. A cada reunião, uma nota era publicada com um breve resumo que apresentava as discussões, os desdobramentos, as dificuldades e, ao mesmo tempo, convocava a participação daqueles que não haviam se incorporado ao processo ainda. Constatamos isso com reportagens, como: “Cada menor abandonado terá o seu próprio lar", em que se afirmava: "Toma grande vulto esse movimento idealizado por Folha de Caxias". Em uma das reuniões realizadas, foi indicada uma comissão para que fosse à Cidade dos $M_{e n i n o s}^{5}$, conversar com Dom Odilão e uma ida à Petrópolis, para tratar da criação do Patronato. O jornal apresentava essas ações como uma "iniciativa de redenção" e com uma possibilidade de "vitória":

\footnotetext{
${ }^{5}$ A Cidade dos Meninos, instalada na década de 1940 na 3a gleba do núcleo colonial, foi uma instituição que contribuiu no projeto de uso e de controle do território próximo à capital federal. Tal organização foi responsável pela constituição de um "trabalhador nacional" através da formação do trabalho agrícola, principalmente.
}

Periódico Horizontes - USF - Itatiba, SP - Brasil - e019046 


\begin{abstract}
Parece que se constituirá uma grande vitória da sociedade caxiense idéia levantada por este jornal visando a criação em Caxias de um patronato de menores desvalidos. A ressonância encontrada desde o início nas autoridades responsáveis do Município; o apoio que a opinião pública demonstrou, as facilidades encontradas em certos setores do governo, levam-nos a ter com decidida firmeza, o êxito mais absoluto desse pensamento (CADA MENOR ABANDONADO..., 19/06/1955, p.1).
\end{abstract}

Essa reportagem era acompanhada de duas fotos: uma, da referida reunião e outra, do momento de explanação do delegado ao capelão da Cidade dos Meninos, Dom Odilão. Essa visita das autoridades à Cidade dos Meninos para conversarem com o capelão da mesma, Dom Odilão Moura, foi fundamental para os rumos da história do Patronato São Bento, pois foram tratara respeito da possibilidade do Mosteiro da antiga Fazenda São Bento abrigar "os menores abandonados".

É partir desses esforços que setores da Igreja Católica, já vinculados a obras de assistência a infância em Duque de Caxias, assumiram um protagonismo na criação do Patronato. Recebidos de forma "acolhedora" pelo capelão, naquele "aprazível recanto", o delegado Amil Nei Richard "em nome dos presentes", fez "sentir àquele sacerdote, Dom Odilão Moura", o objetivo que os “levava ao seu encontro. E disse que por iniciativa de um jornal local, havia sido lançada a ideia da fundação de um patronato em Caxias e que se chegou à conclusão de que a Fazenda de São Bento era muito apropriada para isso" (CADA MENOR ABANDONADO..., 19/06/1955, p.1). O delegado relatou ainda que o presidente do Instituto Nacional de Imigração e Colonização (INIC) afirmou que estaria "o Frei Odilão capacitado a dar a solução para o caso". Dessa forma, disse "que a comissão desejava dele um pronunciamento a respeito" (CADA MENOR ABANDONADO..., 19/06/1955, p.1).

Observamos na reportagem o uso de qualidades enaltecedoras do espaço e do próprio sacerdote. Diante do relato do delegado, o jornal apontava o posicionamento deque o Capelão "era radicalmente favorável à ideia. Mas que na realidade, não Ihe cabia a palavra final, mas sim ao Bispo Diocesano de Petrópolis, Dom Manoel Pedro da Cunha Cintra", e complementava "que em nome da Diocese solicitara ao Instituto de Imigração a Fazenda São Bento, para a fundação de um convento" (CADA MENOR ABANDONADO..., 19/06/1955, p.1). Na mesma reportagem, era dada a informação de que "o Frei Odilão julga que à nobreza e ao sentido humano e cristão desse movimento, o Bispo de Petrópolis não resistirá e dará a concessão imediatamente". Isso posto, a comissão se dirigiu à Fazenda São Bento para conhecer as instalações e, segundo a reportagem, 
todos da comissão (composta por Dr. Ari Fontenele, o Sr. Francisco Corrêa, o Dr. Amil Richaid, a reportagem de A Folha de Caxias, o Sr. Guilherme C. P.de Freitas, representando a Associação Comercial e "pessoas gradas") "ficaram deveras impressionados com a grandiosidade daquela obra" (CADA MENOR ABANDONADO..., 19/06/1955, p.1).

Outras reportagens comemoravam o êxito da campanha: "vitoriosa a iniciativa da Folha de Caxias em prol do Patronato de Menores" com "todas as autoridades municipais solidárias com o movimento humanitário" (É UMA GRANDE VITÓRIA..., 26/06/1955, p.5). Essas frases estavam próximas à fotografia de meninos em situação de abandono, sob a legenda: "em cada esquina um bloco de miseráveis. São brasileiros, são caxienses; merecem a nossa atenção!":

Figura 1 - Imagem de 3 "menores" na rua em Duque de Caxias

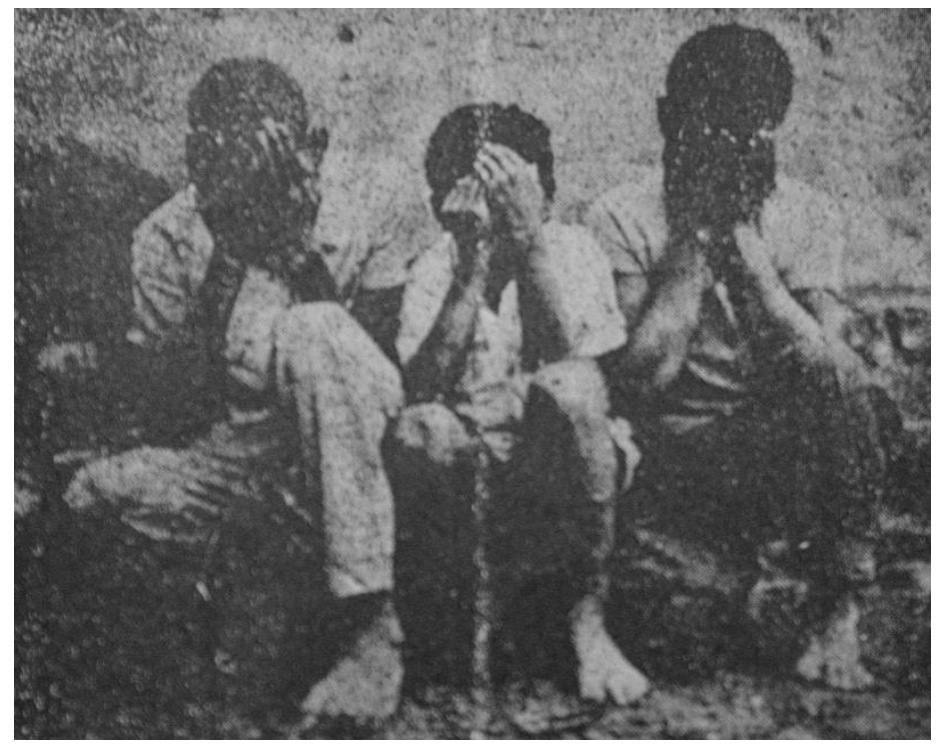

Fonte: É uma grande vitória da sociedade caxiense, 26/06/1955, p.5.

As reuniões, os resultados das mesmas, as autoridades envolvidas, os encaminhamentos, as negações, as mudanças de planos diante dos indeferimentos, todas essas questões eram divulgadas pela A Folha de Caxias. O balanço da segunda reunião era novamente informado e se destacava a pendência de autorização do bispo quanto ao uso da Fazenda São Bento, de acordo com o encontro na Cidade dos Meninos. Em julho, outra reunião era marcada e divulgada no jornal: "Reunião pró-infância desvalida", assim como a descrição de que seria tratada pessoalmente com o bispo Dom Manoel Pedro, a liberação da Fazenda para o fim de criação do 
Patronato (REUNIÃO PRÓ-INFÂNCIA DESVALIDA, 03/07/1955, p.1).

Em agosto de 1955, surgia a notícia sobre o desdobramento da conversa com o bispo. Não havia uma negação do Bispo Dom Manoel Pedro, mas ele "ponderou que o Instituto Ihe havia cedido apenas a sede, isto é, o grande casarão". o jornal afirmava que "a realidade do fato não vinha ao encontro do desejo da Comissão, que não desejava só a casa, mas também terras para que os menores a cultivassem" (AMPARO AOS MENORES DESVALIDOS, 14/08/195, p.1).

A reportagem registrava a promessa do Bispo Dom Manoel Pedro em "comparecer pessoalmente ao Instituto de Colonização, para pleitear deste a concessão para exploração de uma gleba próxima à sede da Fazenda, com o que se beneficiará a Comissão" (AMPARO AOS MENORES DESVALIDOS, 14/08/195, p.1). Assim, percebemos a entrada da Igreja Católica para a comissão que estava responsável em colocar em prática o projeto do Patronato: "Frei Odilão incorporou-se também à nossa campanha e vem trabalhando ativamente. Está preparando os estatutos da Sociedade que se formará." (SERÁ NA FAZENDA S BENTO..., 28/08/1955, p.1). D. Odilão se tornou o autor dos estatutos da Associação Beneficente de Menores, destinada a coordenar os trabalhos de institucionalização do Patronato.

Assim, meses depois ocorria nova reunião "promovida por FOLHA DE CAXIAS para estudo do problema do menor abandonado" (EM MARCHA A CAMPANHA DO MENOR, 25/09/1955, p.1, grifos do original), que passaria a tratar da fundação de uma Associação, que seria responsável por conduzir a criação do Patronato. Nessa mesma reportagem era apresentado o estudo feito por Dom Odilão, que resultou na criação dos Estatutos da Associação Beneficente de Menores (ABM).

Deste feito objetivou-se estudo e emenda do estatuto da Associação Beneficente de Menores confeccionado por d. Odilon Moura. O seu trabalho, que consta de 3 laudas datilografadas, pouco teve a ser modificado, sendo ao fim da reunião aprovado por unanimidade. [...]

A ABM (Associação Beneficente de Menores) terá por diretoria do seu Conselho Administrativo o Juiz de Direito, o Prefeito, o presidente da Câmara, o Delegado, o Presidente da Associação Comercial, um representante da Imprensa e três sócios da ABM eleitos trienalmente pela Assembléia dos sócios (EM MARCHA A CAMPANHA DO MENOR, 25/09/1955, p.1).

Foram transcritos pela A Folha de Caxias alguns dos artigos do estatuto da ABM: o artigo 3ㅇ que tratava da "fundação e manutenção de um estabelecimento de internação dos menores", do "auxílio permanente às famílias necessitadas" enquanto o 5, falava da assistência integral 
que deveria ser oferecida a esses "menores" (EM MARCHA A CAMPANHA DO MENOR, $25 / 09 / 1955$, p.1). Nas reportagens subsequentes, foram apresentados os diretores da $A B M$ escolhidos na reunião, e suas respectivas funções na $A B M$, assim como os órgãos aos quais estavam vinculados. As manchetes indicavam o andamento da criação do patronato: "Reunião de autoridades em benefício do menor" (REUNIÃO DE AUTORIDADES..., 13/11/1955, p.1), “Em Franco andamento a Campanha do Menor" (EM FRANCO ANDAMENTO..., 13/11/1955, p.5) e “Posse da diretoria do Patronato de Menores" (POSSE DA DIRETORIA..., 17/11/1955, p.1).

O início da atuação da $A B M$ se caracterizou pelo atendimento aos "menores trabalhadores". Isso consistiu no trabalho junto aos meninos nas atividades de engraxate, vendedores na rua, entre outros. No ano de 1957, houve um trabalho com as meninas também. De 1955 a 1956, foram realizadas inúmeras ações para que a ABM conseguisse um espaço de internamento. Por esse motivo, o trabalho junto aos "menores" foi realizado nas ruas do distritosede, que equivalia ao Centro comercial do município.

Em 1955, houve o lançamento da pedra angular do Patronato e a continuidade das reportagens que tratavam, de forma efusiva, sobre as ações da $A B M$, até porque a Associação continuava empreendendo esforços para a construção de um espaço de internamento que não havia sido consolidado ainda no ano de sua instituição. Dessa maneira, a campanha pelo Patronato continuava constante no jornal e seguiu pelos anos posteriores. No final de 1956 foi publicada uma matéria sobre "Fatos Principais Ocorridos em Caxias", entre os quais destacamos: a reunião de 130 "menores para serem amparados pela ABM", o lançamento da pedra fundamental do Patronato de Menores da ABM, a inauguração da sede da ABM, a posse do novo Juiz de Direito da Comarca, Dr. Helio Albernaz Alves (que criou o Comissariado de Menores da cidade e foi homenageado na Associação Comercial). Todos esses assuntos eram desdobrados como minuciosa descrição pelo jornal, dando a ver o empenho do mesmo na "Campanha do menor" (FATOS PRINCIPAIS OCORRIDOS EM CAXIAS, 31/12/1956, p.5).

\section{A título de conclusão: “A iniciativa dêste jornal está, pois, coroada de pleno êxito"}

Em abril de 1956, foi lançada a campanha financeira da ABM para arrecadar fundos para a instituição (INÍCIO DA GRANDE CAMPANHA..., 08-09/04/1956, p.5). A cada matéria, havia a 
confirmação de que com a arrecadação seria construído um Patronato para dar assistência aos menores em situação de abandono:

A grande campanha em favor da infância desvalida, iniciada por FOLHA DE CAXIAS, em colaboração com a Sé Episcopal de Petrópolis e com as autoridades municipais, será aberta solenemente, hoje, às 19 horas, no salão nobre da Associação Comercial de Duque de Caxias, com um grande festival artístico.

A iniciativa dêste jornal está, pois, coroada de pleno êxito. Uma grande campanha financeira será empreendida para a construção do Patronato que abrigará o incontável número de caxienses de amanhã que vagam por nossas ruas sem qualquer amparo material ou moral. Ser-lhes-á dada tôda assistência material ou espiritual de que carecem e uma formação que lhes garantirá o futuro e dará ao nosso município homens trabalhadores e capazes (HOJE, O INÍCIO OFICIAL DA CAMPANHA, 29-30/04/1956, p.2).

Interessante observar que A Folha de Caxias continuava articulando o consenso e buscando legitimidade para a criação do Patronato com matérias alusivas a criação da $A B M$ e ao tema dos menores abandonados:

\begin{abstract}
Pelas estatísticas que nos foram apresentadas o problema é gravíssimo. Tratase de centenas e centenas de menores, de ambos os sexos, que desamparados, sem nenhum esteio de família bem constituída, andam ao léo, presa fatal das mais vis paixões. Aliás quem poderia falar com eloquência sôbre a gravidade do problema, melhor do que nós, seria a Delegacia de Polícia de Caxias que registra em seu arquivo doloríssimos episódios de deliquência infantil nesta cidade (HOJE, O INÍCIO OFICIAL DA CAMPANHA, 29-30/04/1956, p.2).
\end{abstract}

Observamos que o jornal atuou na institucionalização de diferentes ações junto ao tema dos menores, desde as constantes matérias sobre crimes cometidos pelas crianças que vagavam pelas ruas da cidade, pautando o assunto pela imprensa, os apelos feitos para que autoridades locais como juízes, vereadores, prefeitos buscassem soluções, até a organização das reuniões que resultaram na fundação da ABM e do patronato para "menores desvalidos". Faria Filho (2002), noutro contexto e noutro local, demonstrou semelhanças ao registrar que na sua pesquisa: "o jornal foi visto como uma importante estratégia de construção de consensos, de propaganda política e religiosa, de produção de novas sensibilidades, maneiras e costumes. Sobretudo os jornais foram vistos como importante estratégia educativa" (FARIA FILHO, 2002, p.134). 
Um articulista de codinome "LYNX" opinou sobre a nova iniciativa da ABM, tendo-a considerada muito oportuna e com grande possibilidade de acabar com o problema dos meninos que perambulavam pelas ruas: "Uma vez internados, os menores sofreriam uma completa reeducação, tanto na parte escolar, como na social com preceitos de civilidade e higiene". O articulista valorizava a oportunidade dos menores receberem uma formação profissional voltada para trabalhos manuais, de artesanato e agrícolas e requeria financiamento público para a instituição (LYNX..., 29-30/04/1956, p.3). Praticamente, a cada edição do jornal, era publicado um artigo ou havia uma manchete que chamava a atenção para a campanha financeira em prol da construção do Patronato (GRANDE ENTUSIASMO NO INÍCIO..., 06-07/05/1956, p.1).

Assim, por meio da campanha jornalística se organizavam "operações de hegemonia", meios pelos quais a concepção de mundo e os valores de um grupo são difundidos, reforçados e estimulados "capilarmente" pela sociedade, tornando-se hegemônicos (BUTTIGIEG, 2003, p.47). Sob a defesa de "amparar a infância desvalida", a campanha promovida pelo jornal defendia interesses de comerciantes, empresários e políticos, que tornavam a desigualdade social, percebida na vulnerabilidade social das crianças, em problema policial, jurídico, filantrópico e de embelezamento da cidade.

Na construção do consenso operado pela imprensa, Dom Odilão foi convidado a publicar na A Folha de Caxias artigos que abordavam a situação do "Menor Abandonado". Examinava a "situação de menores desamparados na sociedade moderna" e salientava quais seriam as razões de tal situação: "Muitas seriam as causas que iriam surgindo da primeira pesquisa: a guerra, o pauperismo, a inflação, as favelas, o êxodo rural, o despudor tornado rotina, os crimes, o descaso dos poderes públicos para com os males sociais, etc." (SEÇÃO: MENORES ABANDONADOS, 0102/07/1956, p.4)

Na terceira publicação da série "Menores Abandonados", o padre demonstrava um contato próximo aos meninos e descrevia o comportamento dos que viviam nas ruas. Posto que "o número de menores abandonados filhos naturais é muito grande", avaliava que se tratava de uma infância destinada ao crime ou a ele submetida: "o meretrício, [...] o lenocínio, a embriaguez, o crime, a doença, a destruição da família, a redução da mulher à escravidão ao vício, é fonte fecunda de crianças abandonadas". Concomitante a isso, parabenizava a Câmara Municipal de Vereadores por enfrentar o "meretrício" e atenuar essa que seria uma das causas 
principais "do abandono de menores" (DOM ODILÃO. Menores..., 15-16/07/1956, p.4).

$\mathrm{Na}$ última reportagem da série sobre os menores abandonados alegava que "nem todo menor abandonado é um delinquente", embora "todo menor abandonado [...] está colocado em situação de se tornar um delinquente" (DOM ODILÃO. Menores..., 22-23/07/1956, p.4). Reiterava que "o estado moderno enfrenta o problema de menores delinquentes mais com medidas preventivas que repressivas", de acordo com o direito penal brasileiro. Afirmava que muitos menores atendidos pelo Serviço de Assistência aos Menores(SAM) ${ }^{6}$ eram delinquentes, assim como reafirmava a tese do abandono como um caminho para o crime. Salientava a atuação do juiz como "um ação enérgica e persistente, como a que agora se inicia em Caxias com a figura, rara em nossos dias, [...] contra o lenocínio, prostituição, jôgo, embriaguês, furto, em muito diminuiria a criminalidade infantil" (DOM ODILÃO. Menores ..., 22-23/07/1956, p.4). Na sua concepção, as ruas eram vistas como uma escola para a criminalidade, pois indagava retoricamente se as ruas no município eram "um gôrgo caldo de cultura para a proliferação de menores criminosos?" (DOM ODILÃO. Menores abandonados, 22-23/07/1956, p.4). Percebemos nesses artigos uma narrativa religiosa católica, assim como, o reforço de que a solução para essa determinada infância seria a internação.

As manchetes caracterizavam a atuação da $A B M$ como um dos maiores movimentos já realizados no município (A ABM. É O MAIOR MOVIMENTO..., 16-17/09/1956, p.6). Outras personalidades expressavam seu apoio no próprio jornal, como Frei Joaquim, vigário da Paróquia de Santo Antônio. Ele citava que havia "incompreensão de muitos", mas A Folha não deveria esmorecer nesta campanha (TEMOS O DEVER DE..., 23-24/09/1956, p.1). Essa divulgação das ações da $A B M$, atrelada ao movimento dos diferentes agentes, contribuiu para a consolidação da instituição no município. Muitas dessas reportagens faziam referência à campanha em favor do "menor", incentivada em diferentes momentos pelo jornal.

Como vemos no discurso de D. Odilão e no exame do jornal, a campanha de financiamento do Patronato figurava nas páginas do jornal ao lado das matérias que continuavam a tratar dos crimes cometidos por menores, da presença deles nas ruas e das

${ }^{6}$ O Serviço de Assistência aos Menores (SAM) foi criado em 1941 com o objetivo de centralizar e orientar os serviços de assistência a "menores desvalidos e delinquentes, internados em estabelecimentos oficiais e particulares" (RIZZINI, 2011, p.264). 
tentativas de enfretamento do crime de lenocínio ao qual estes menores (em sua maioria meninas), estavam expostos. Porém, se a campanha do jornal foi exitosa na criação do Patronato, o mesmo não ocorreu no enfrentamento do lenocínio. A análise da fonte jornalística permite conhecer os conflitos e as resistências que ocorreram entre autoridades judiciárias e os vereadores de Duque de Caxias sobre esse tema (A JUSTIÇA APOIA A COMISSÃO DE INQUÉRITO..., 8/11/1953, p.1). O aspecto das resistências encontradas não minimiza a importância da campanha promovida pelo jornal, pelo contrário, potencializa as perspectivas do jornal como fonte, porque:

\begin{abstract}
O jornal é um documento histórico singular, que tem no mosaico das notícias que estampa a sua característica. Ele trabalha com diversos grupos, oferece atrativos para diferentes interesses, necessita garantir os olhares do público, por mais diversificado que este seja. Apesar do direcionamento ideológico presente nos jornais, não encontramos em suas folhas apenas 'uma' história, mas diversas. Daí sua riqueza (GONÇALVES NETO, 2002, p.208).
\end{abstract}

O jornal é uma fonte importante para pesquisas em história da educação local, o que se acentua pela incipiente oferta de arquivos de pesquisa públicos como políticas de acesso. Mas em sua utilização, não podemos desvincular o compromisso educativo ao qual esse veículo se propõe, como afirmou Faria Filho (2002). Na investigação sobre a história do Patronato São Bento, a imprensa foi importante tanto pela incipiência de outras fontes, mas, principalmente, porque o jornal A Folha de Caxias foi um grande mobilizador da campanha pela criação do Patronato. Atuou deliberadamente como aglutinador de diferentes agências que cooperaram na criação da Associação Beneficente de Menores (ABM) e, posteriormente, na institucionalização do Patronato São Bento. Da mesma forma que a idealização das primeiras reuniões quando ainda não era $A B M$, a campanha de fundação da $A B M$ e a construção do Patronato estavam atreladas, desde seu início, à imprensa local, com diferentes manchetes que corroboraram a necessidade de tais feitos, assim como convocaram a opinião pública a acionar a sociedade política.

Dessa forma, a identificação das diferentes reportagens sobre o "menor"; a atuação dos diferentes juízes; a convocação da sociedade e do poder público para uma ação contundente em relação ao "problema da infância abandonada"; os destaques dados sobre o crescimento populacional da cidade, as críticas às reportagens da capital federal em relação à construção da

Periódico Horizontes - USF - Itatiba, SP - Brasil - e019046 
imagem violenta de Duque de Caxias; a necessidade de impressão de uma imagem mais moderna de Caxias; as inúmeras matérias sobre a "criminalização dos menores"; a campanha contra o lenocínio; apontaram para o estabelecimento de um espaço de internamento, o Patronato, como solução, de acordo com o jornal. Tudo isso permitiu a identificação das ações de controle e de ordenamento impostas, associadas à judicialização do tratamento dessa infância através da internação endereçada ao segundo distrito. Nota-se assim, o imbricamento das questões sobre o controle do espaço urbano e de suas populações com a temática da remoção dos "menores abandonados" da centralidade do espaço urbano.

Apenas em julho de 1959, foi instituído o Patronato no território do Núcleo Colonial, da antiga Fazenda São Bento. O Patronato é a ação organizada pela ABM para que a mesma atinja a sua finalidade como descrito no artigo 3ำ, do Estatuto de 1956 da ABM. Haveria a fundação e manutenção de um estabelecimento de internação de menores, que seria denominado Instituto Profissional São José. De acordo com o relatório de 1957, encontramos a referência ao início da construção de um edifício para o patronato, destinado ao recolhimento dos "menores abandonados", segundo a redação original, além da assistência aos menores trabalhadores de rua. Notamos também que a localização da instituição passou por mudanças ao longo do tempo. Primeiramente, a sede foi chamada de Casa São José e ficava localizada num hotel, onde era pago um aluguel, entre 1956 e 1957. Porém, em 1o de junho de 1959, com o início do internamento dos meninos, a sede passou a funcionar no espaço da antiga Fazenda São Bento. Com o fato de terem se instalado na Fazenda São Bento, passou a ser chamado de Instituto Profissional São Bento, em substituição ao de Instituto Profissional São José.

\section{Referências}

A ABM é o maior movimento de apoio ao menor já encetado em Duque de Caxias. Folha da Cidade. Duque de Caxias, ano IV, n.13, 16 e 17 set. 1956, p.06.

A JUSTIÇA apoia a comissão de inquérito que investiga a extensão do lenocínio: ouvido o juiz Dr. Navega Creton, A Folha de Caxias, Duque de Caxias. ano I, n. 11, p. 1, 8 nov. 1953.

AMPARO a infância abandonada de Caxias. Folha de Caxias. Duque de Caxias, ano II, n.60, 29 maio 1955, p.01. 
AMPARO a infância abandonada de Caxias, Folha de Caxias. Duque de Caxias, ano II, n.62, 12 jun.1955, p.04.

AMPARO aos menores desvalidos. Folha de Caxias. Duque de Caxias, ano III, n.71, 14 ago. 1955, p.01.

AS AUTORIDADES e o lenocínio. Folha de Caxias, Duque de Caxias, ano III, n.75, 11set. 1955, p.01.

BALANÇO trágico de Caxias: 800 crianças desamparadas. Folha de Caxias, Duque de Caxias, ano II, n.62, 12 jun.1955, p.05.

BRAZ, A. A.; ALMEIDA, T. M. A. De Merity a Duque de Caxias: encontro com a história da cidade Duque de Caxias. Duque de Caxias: APPH-CLIO, 2010.

BUTTIGIEG, J. A. Educação e hegemonia. In: COUTINHO, C.N. (Org.). Ler Gramsci, entender a realidade. Rio de Janeiro: Civilização Brasileira, 2003, p.39-49.

CADA menor abandonado terá o seu próprio lar. Folha de Caxias, Duque de Caxias, ano II, n.63, p.1, 19 jun.1955.

CAXIAS ERA a terra do vício e do crime. Folha da Cidade. Duque de Caxias, ano IV, n.9, p.15, 2627 ago. 1956.

CAXIAS, ESSA incompreendida. A Folha de Caxias. Duque de Caxias, ano I, n.7, p.3, 2-3 out. 1953.

COM 17 ANOS já está na senda do crime: em outro local do presente edição uma notícia sobre vários assaltos praticados por menores em nossas casas comerciais. A Folha de Caxias, Duque de Caxias, ano I, n.8, p.2, 11 out. 1953.

COMO FALOU o juiz - a infância abandonada. A Folha de Caxias, Duque de Caxias, ano I, n.32, p.4, 25 abr. 1954.

DOM ODILÃO. Menores abandonados. Folha da Cidade, Duque de Caxias, ano IV, n.1, p.4, 1-2 jul. 1956.

DOM ODILÃO. Menores abandonados. Folha da Cidade, Duque de Caxias, ano IV, n.3, p.4, 1516 jul. 1956.

DOM ODILÃO. Menores abandonados. Folha da Cidade, Duque de Caxias, ano IV, n.4, p.4, 2223 jul. 1956.

É UMA grande vitória da sociedade caxiense. Folha de Caxias, Duque de Caxias, ano 2, n. 64, p.5, 26 jun. 1955. 
EM CAXIAS: crianças na senda o crime. A Folha de Caxias, Duque de Caxias, ano I, n.25, p.3, 21 fev. 1954.

EM FRANCO andamento a campanha do menor. Folha de Caxias, Duque de Caxias, ano II, n.83, p.5, 13 nov. 1955.

EM MARCHA a campanha do menor. Folha de Caxias, Duque de Caxias, ano III, n.77, p.1, 25 set. 1955.

ENGRAXATES barulhentos. A Folha de Caxias, Duque de Caxias, ano I, n.3, p.4, 5 set. 1953.

FATOS principais ocorridos em Caxias no ano de 1956. Folha da Cidade, Duque de Caxias, ano IV, n.27, p.05, 30-31 dez. 1956.

FARIA FILHO, L. M. O jornal e outras fontes para a história da educação mineira do século XIX: uma introdução. In: ARAÚJO, J. C. S.; GATTI JÚNIOR, D. (Orgs.). Novos temas em história da educação brasileira: instituições escolares e educação na imprensa. Campinas, SP/ Uberlândia, MG: Autores Associados/EDUFU, 2002, p.133-150.

GONÇALVES NETO, W. Imprensa, civilização e educação: Uberabinha (MG) no início do século XX. In: ARAÚJO, J. C. S.; GATTI JÚNIOR, D. (Orgs.). Novos temas em história da educação brasileira: instituições escolares e educação na imprensa. Campinas, SP/ Uberlândia, MG: Autores Associados/EDUFU, 2002, p.197-225.

GRANDE entusiasmo no início da campanha do menor desamparado. Folha da Cidade. Duque de Caxias, ano III, n.109, p.1, 6-7 maio 1956.

INFÂNCIA abandonada. A Folha de Caxias, Duque de Caxias, ano I, n.46, p.3, 29 ago. 1954.

INÍCIO da grande campanha financeira em benefício do menor. Folha da Cidade, Duque de Caxias, ano III, n.103, p.5, 8- 9 abr. 1956.

INSULTO as famílias e a decadência moral. A Folha de Caxias, Duque de Caxias, ano I, n.22, p.1, 31 jan.1954.

HOJE, o início da campanha em favor do menor desamparado. Folha de Caxias, Duque de Caxias, ano III, n.108, p.2, 29 e 30 abr. 1956.

JUIZ de menores. A Folha de Caxias, Duque de Caxias, ano II, n.55, p.1, 12 dez. 1954. Caxias, ano I, n.10, p.4, 25 out. 1953.

LYNX. Problemas caxienses: menores amparados. Folha da Cidade, Duque de Caxias, ano III, n.107, p.3, 29-30 abr. 1956.

MENDONÇA, S. R. Estado, educação rural e influência norte-americana no Brasil (1930-1961).

$$
\text { Periódico Horizontes - USF - Itatiba, SP - Brasil - e019046 }
$$


Niterói: Editora da UFF, 2010.

MENORES abandonados roubam casas comerciais em Caxias: meios de evitar a perdição-soltos depois de presos. A Folha de Caxias, Duque de Caxias, ano I, n.8, p.6, 11 out. 1953.

MENORES no cinema. Folha de Caxias, Duque de Caxias, ano II, n.56, p.3, 1 maio 1955.

NA AVENIDA Duque de Caxias - escuridão e perigo. A Folha de Caxias, Duque de Caxias, ano I, n.22, p.05, 31 jan.1954.

OBRA inadiável: amparar a infância desvalida. A Folha de Caxias, Duque de Caxias, ano II, n.53, p.1, 21 nov. 1954.

OLHE as crianças meritíssimo juiz. A Folha de Caxias, Duque de Caxias, ano I, n.35, p.1, 16 maio 1954.

ONDA de assaltantes. A Folha de Caxias, Duque de Caxias, ano I, n.37, p.1-4, maio 1954.

O víclO assalta as ruas. A Folha de Caxias, Duque de Caxias, ano I, n.42, p.03, 18 jul. 1954.

PASSETTI, Edson. Crianças carentes e políticas públicas. In: PRIORI, Mary Del (Org.) História das Crianças no Brasil. São Paulo: Contexto, 2004. p. 146-175.

PATRIOTISMO e abnegação: o patronato de menores abandonados. A Folha de Caxias, Duque de Caxias, ano I, n.15, p.1, 29 nov. 1953.

PERIGO - salve-se quem puder. A Folha de Caxias, Duque de Caxias, ano I, n.20, p.1, 17 jan.1954.

PERSISTE a jogatina de menores nos parques de diversões. A Folha de Caxias, Duque de Caxias, ano I, n.35, p.1, 16 maio 1954.

POSSE da diretoria do Patronato de Menores. Folha de Caxias, Duque de Caxias, ano III, n.85, p.1, 27 nov. 1955.

POSTO em liberdade o assaltante: terá servido mais esta lição? A Folha de Caxias, Duque de PROSTITUIÇÃO: mal necessário ou fatalidade da vida social. Folha da Cidade, Duque de Caxias, ano III, n.5, p.1, 29 e 30 jul. 1956.

REUNIÃO de autoridades em benefício do menor. Folha de Caxias, Duque de Caxias, ano II, n.83, p.1, 13 nov. 1955.

REUNIÃO pró-infância desvalida. Folha de Caxias, Duque de Caxias, ano II, n.65, p.1, 3 jul. 1955.

Periódico Horizontes - USF - Itatiba, SP - Brasil - e019046 
RIBEIRO, B. O. L.; SILVA, E. F.; SILVA, M. A. A. Jornal como fonte: uma das pontas do iceberg nas narrativas em História da Educação. Cadernos de História da Educação, v.13, n.1, p.219-231, jan./jun.2014.

RIZZINI, I. Meninos desvalidos e menores transviados: a trajetória da assistência pública até a era Vargas. In: PILOTTI, F.; RIZZINI, I. A arte de governar crianças: a história das políticas sociais, da legislação e da assistência à infância no Brasil. São Paulo: Cortez,2011, p.225-286.

SERÁ na fazenda S. Bento, o patronato de menores abandonados. Folha de Caxias, Duque de Caxias, ano III, n.73, p.1, 28 ago. 1955.

SOUZA, M. S. Escavando o passado da cidade: história política da cidade de Duque de Caxias. Duque de Caxias: APPH-Clio, 2014.

TEMOS o dever de socorrer o nosso semelhante. Folha da Cidade, ano IV, n.14, p.1, 23-24 set. 1956.

UM APELO ao sr secretário de Segurança Pública. A Folha de Caxias, Duque de Caxias, ano I, n.20, p.02, 17 jan.1954.

\section{AGRADECIMENTOS}

Agradecemos a cada missanga que tem composto esse colar que foi a pesquisa sobre o Patronato São Bento. E deixamos um agradecimento especial à Fatima David (in memoriam). Fatima David, presente hoje e sempre!

Recebido em março de 2018.

Aprovado em abril de 2019. 